\title{
Perfil Sociolinguístico e Alimentar de Crianças Assistidas em Creches Públicas e Privadas
}

\author{
Feeding and Sociolinguistic Profile of Children Attended in Public and Private Daycare \\ Centers
}

\author{
Priscilla Mayara Estrela Barbosa*a; Januária Lopes de Melo ; Moisés Andrade dos Santos de Queiroz ; Andréa Cintia \\ Laurindo Porto ${ }^{\text {a }}$ Luciana Bernardino de Oliveira ${ }^{\text {a }}$ Izabella dos Santos Nogueira de Andrade ${ }^{a}$
}

\author{
${ }^{a}$ Faculdade Pitágoras. CE, Brasil. \\ 'Universidade de Fortaleza. CE, Brasil. \\ 'Hospital Geral de Fortaleza. CE, Brasil. \\ *E-mail: priscillamayara@yahoo.com.br
}

\begin{abstract}
Resumo
Com o objetivo de comparar o perfil sociolinguístico e alimentar de crianças de um a três anos, que frequentam creches públicas e privadas no município de Fortaleza, em tempo integral, foi realizado este estudo quali-quantitativo, descritivo-comparativo, transversal, no qual foram avaliadas 89 crianças com faixa etária entre um e três anos de idade cronológica, 41 em uma creche pública e 48 em uma privada. Para isso foi aplicado um protocolo de avaliação das habilidades linguísticas (fonológicas, semânticas, morfossintáticas e pragmáticas) e alimentação. Quanto às habilidades fonológicas se verificou que a inteligibilidade de fala foi o principal aspecto alterado e mais encontrado na creche pública. A respeito da aquisição das habilidades semânticas foram identificados achados discrepantes entre as creches, em especial, na seleção de palavras adequadas e expressão de ideias e conceitos, com desempenho superior das crianças na instituição privada. Não houve diferenças importantes entre as creches para aquisição das habilidades morfossintáticas. As habilidades pragmáticas foram as que obtiveram maiores diferenças, com melhor desempenho das crianças da creche privada, em todos aspectos avaliados no protocolo. Sobre a alimentação foram obtidos resultados semelhantes quanto à consistência alimentar e postura, constatando o uso prolongado do utensílio mamadeira para alimentação em ambas as creches e maior prevalência de crianças que se alimentam sem ajuda na creche privada. Pode-se perceber que o contexto socioeconômico e cultural influencia o desenvolvimento da linguagem e da alimentação infantis, visto que as crianças da creche particular apresentaram melhor performance em quase todos os aspectos analisados.
\end{abstract}

Palavras-chave: Desenvolvimento Infantil. Crianças. Creche. Linguagem.

\begin{abstract}
In order to compare the feeding and sociolinguistic profile of children attended in public and private daycare centers in the city of Fortaleza enrolled on a full-time basis. Quali-quantitative, descriptive cross-sectional study, evaluated 89 children aged 1 and 3 years old, 41 in public and 48 in the private childcare centers. A protocol assessment was performed of linguistics abilities (phonological, semantic, morphosyntax and pragmatic) and feeding. About the phonological abilities, a significant predominance was checked, being the unintelligible speech the main altered aspect, especially in the public center. Concerning semantic abilities discrepant findings were determined between the daycare centers, particularly in selection of adequate words and concept and idea expression, with improved performance of children in the private daycares. There was no difference between the daycares, for morphosyntax abilities acquisition. The pragmatic abilities revealed larger differences between the daycare centers, in which all the evaluated aspects were statistically significant and the children in the private daycare centers had better results. About the feeding, similar findings were obtained to food consistence, posture and tools, although there were divergences related to use of nursing bottle and feeding independence. It was concluded that the socioeconomic and cultural context influence in linguistic and feeding development, because the private daycares children presented better performance in almost all the evaluated aspects.
\end{abstract}

Keywords: Child Development. Child. Daycare Centers. Language.

\section{Introdução}

A dinâmica da sociedade atual, com a inserção da mulher no mercado de trabalho, exige que as famílias se reorganizem no cuidado com os bebês e crianças. Muitas mães, após o término da licença-maternidade, precisam deixar seus filhos aos cuidados de outras pessoas para retornar a sua função trabalhista. Com isso, a opção adotada pela maioria das mães é a inserção das crianças em creches por longos períodos (SANTOS et al., 2008).

Creches e pré-escolas são instituições destinadas a educar e cuidar de crianças pequenas, compreendendo a faixa etária de zero a seis anos (ARAUJO et al., 2010). Segundo a Lei de Diretrizes e Bases da Educação Nacional (LDBEN), essa faixa etária abrange a Educação Infantil, que é a primeira etapa da Educação Básica e tem como finalidade o desenvolvimento integral da criança em seus aspectos físico, psicológico, intelectual e social (BRASIL, 1996).

Esses primeiros anos de vida são considerados essenciais para o desenvolvimento infantil, visto que há maior crescimento cerebral e formação de mais conexões neuronais (MORETI et al. 2017). Portanto, a estimulação de crianças, nos mais diversos campos do desenvolvimento se torna relevante para a aquisição de conhecimentos e de habilidades que fará parte do indivíduo (OLIVEIRA, FLORES, SOUZA, 2012). Ressalta-se que este momento coincide também com o período de maior desenvolvimento da linguagem, esta se constitui de 
componentes funcionais, tais como: Fonologia, Semântica, Morfossintaxe e Pragmática. Isto corresponde às habilidades linguísticas de forma (Fonologia e Morfossintaxe), conteúdo (Semântica) e uso efetivo na comunicação (Pragmática) (LIMA et al., 2007).

A interação destas habilidades possibilita a constituição e organização do desenvolvimento linguístico, em que há a formação do inventário fonético e sistema fonológico da criança (BRASÍLIA, 2016). Estes dão subsídios para que a linguagem oral se estabeleça e, dessa maneira, haja comunicação verbal, aquisição de conhecimentos do meio e socialização (SOUZA et al., 2008).

Todavia, alguns problemas podem acarretar alterações na aquisição e desenvolvimento da linguagem, entre esses a ocorrência de queixas alimentares, além da falta de atenção familiar (BISCEGLI et al., 2007). Dado que desenvolvimento integral da criança depende tanto dos cuidados que envolvem a dimensão afetiva quanto dos aspectos biológicos do corpo (PALLADINO; CUNHA; SOUZA, 2007).

Desse modo, explicita-se a necessidade de atentar para o desenvolvimento infantil alimentar e linguístico, especificamente, em crianças pequenas em diferentes realidades socioeconômicas e culturais, visto que esta é base para as condições de crescimento, socialização e aprendizagem. Nessas circunstâncias, este artigo mostra o resultado de um experimento, que objetivou comparar o perfil sociolinguístico e alimentar de crianças de um a três anos que frequentam creches públicas e privadas em tempo integral.

\section{Material e Métodos}

\subsection{Delineamento do estudo}

O estudo foi submetido e aprovado pelo Comitê de Ética em Pesquisa da Universidade de Fortaleza - UNIFOR sob o parecer de $n^{\circ} 105 / 09$. Seus aspectos éticos obedeceram à Resolução 196/96 da Comissão Nacional de Ética em Pesquisas (CONEP), Conselho Nacional de Saúde (CNS) - Ministério da Saúde. Os termos de Consentimento Livre e Esclarecido foram assinados pelos pais das crianças e/ou responsáveis das instituições.

Tratou-se de um estudo quantitativo, descritivo/ comparativo, transversal, padronizado, não controlado, desenvolvido no período de maio a dezembro de 2009 em duas creches - pública e privada - do Município de Fortaleza, Ceará. A creche pública Odilon Braveza, instituição vinculada à Secretaria Executiva Regional VI, indicada pela Secretária de Educação do Município de Fortaleza- CE e, a creche privada: Casa da Tia Léa - Sede 01, que apresentou disponibilidade em receber os pesquisadores, também situada na mesma região da instituição pública. Foram eleitas uma creche pública e uma privada para comparar o fator socioeconômico e avaliar seu impacto no desenvolvimento infantil, já que existe uma crença popular de que as escolas privadas são superiores (DEMO, 2007).
Assim, as creches eleitas tinham características semelhantes: pertenciam a mesma localização geográfica da cidade de Fortaleza (regional VI), tinham número de alunos por sala de aula semelhantes, além de estrutura similar das atividades do cotidiano ofertadas aos estudantes (iniciavam com acolhida, com músicas e brincadeiras lúdicas supervisionadas pela professora e auxiliar. Em seguida, atividades em sala de aula. Por conseguinte, o recreio que consiste na oferta de lanche no refeitório e brincadeiras nas áreas comuns, como o pátio. Ao final, mais atividades em sala de aulas com professora e auxiliar, seguida do banho supervisionado, almoço no refeitório e horário de descanso, retornando à sala de aula. Após o descanso, normalmente de 1 hora de duração, atividades lúdicas coletivas antes de irem para casa). Em todas as turmas pesquisadas havia uma professora graduada em Pedagogia e uma professora auxiliar graduanda em Pedagogia.

Como os infantes estavam em tempo integral nas respectivas instituições educacionais, salienta-se a importância das semelhanças na rotina cotidiana escolar as quais as crianças foram submetidas para parear a comparação entre os dois locais de pesquisa.

A seleção do estabelecimento público ocorreu de maneira aleatória. Porém, a escolha de uma creche pública e outra particular permitiu a comparação das diferentes realidades vividas pelas crianças e, a influência do fator sociocultural e econômico no desenvolvimento da linguagem e da alimentação.

Foi adotado como critério de exclusão para a seleção das creches a inserção de um fonoaudiólogo escolar na instituição, já que poderia interferir no desempenho linguístico e alimentar das crianças.

\subsection{Participantes do estudo}

Os sujeitos da pesquisa foram crianças de um a três anos de idade cronológica, de ambos os gêneros, matriculadas em tempo integral, ou seja, mais de seis horas diárias nas creches eleitas para a pesquisa, de segunda a sexta-feira.

Foram excluídos do estudo crianças com alterações ou desvios no desenvolvimento infantil, tais como: diagnóstico de Transtorno do Espectro do Autismo (TEA), Síndrome de Down, Distúrbio Fonológico, Fissuras labiopalatinas, Transtorno do Déficit de Atenção/Hiperatividade (TDAH) e Paralisia Cerebral. E que não faziam pelo menos uma refeição importante (almoço ou jantar) na creche, ou frequentavam outra instituição de ensino, complementarmente.

Essas informações foram obtidas por meio do cadastro de matrícula das crianças, que continha informações relevantes sobre a saúde e o desenvolvimento, bem como a rotina na creche (número de horas durante as quais ficam na instituição, patologias anteriores, cuidados especiais com a alimentação e número de refeições realizadas na instituição), além de conversas com as mães, cuidadoras, professoras e 
coordenadoras das instituições.

Considerando-se os critérios de inclusão e exclusão, a amostra do estudo foi constituída de 89 crianças, sendo 41 crianças da creche pública e 48 crianças da creche privada.

\subsection{Instrumentos e procedimentos de coleta de dados}

Para a coleta de dados foi aplicado o Protocolo de Avaliação Clínica Fonoaudiológica da ABFW: Teste de Linguagem Infantil nas Áreas de Fonologia, Vocabulário, Fluência e Pragmática (ANDRADE et al., 2000). Através desse foram avaliadas as habilidades pragmáticas (funções comunicativas e habilidades conversacionais), semânticas (vocabulário), fonológicas (uso e automatização de fonemas) e morfossintáticas (regras da língua) da linguagem dos participantes. Além disso, também foi analisada a alimentação por meio do protocolo MBGR (GENARO et al., 2009).

$\mathrm{Na}$ primeira semana não houve contato direto com as crianças, mas a presença do pesquisador objetivou estabelecer um vínculo com os infantes e a sua respectiva comunidade escolar, bem como proporcionar maior familiaridade desses com a presença das pesquisadoras, diminuindo a possibilidade da não participação por não se sentir à vontade posteriormente, no momento da avaliação. Esse momento também contribuiu para observação do contexto comunicativo, rotina e convívio interpessoal em sala de aula. Observou-se ainda o contexto comunicativo na sala de aula e no convívio com as outras crianças. Na segunda semana, foram realizadas as avaliações individuais, separadamente utilizando o protocolo.

Cada criança foi avaliada separadamente, em uma sala cedida pelas creches, no período de aproximadamente trinta minutos. Utilizou-se para a avaliação da linguagem uma situação lúdica, utilizando brinquedos cedidos pelas avaliadoras, como jogos de encaixe, bolas, bonecas, quebracabeças, livros infantis e miniaturas de animais e meios de transporte.

Para avaliar a alimentação foi observado um momento de refeição (almoço ou lanche) de cada criança isoladamente no próprio ambiente de refeição do estabelecimento, ou seja, refeitório ou sala de aula. Nesse momento, foi avaliado se havia escape na hora da mastigação, a autonomia de se alimentar sozinha e o de como levava a colher à boca com movimento de pinça.

As pesquisadoras fizeram duas semanas de visitas em cada creche, totalizando 20 dias de convivência nas instituições.

\subsection{Organização e análise dos dados}

O banco de dados foi organizado com a utilização do software SPSS v16 para tabulação e classificação dos resultados e, posteriormente, submetido à apreciação estatística, em que foram utilizados o Teste de Igualdade de Duas Proporções e o Teste Exato de Fisher. O nível de significância adotado foi de $p<0,05$ (5\%), com intervalo de confiança de $95 \%$.

\section{Resultados e Discussão}

Do total de 89 crianças, 47 eram do gênero masculino (52, 2\%). Na creche pública, foram avaliadas 19 meninas $(46,3 \%)$ e 22 meninos $(53,6 \%)$, enquanto na creche privada participaram do estudo 26 meninas $(54,2 \%)$ e 22 meninos (45,8\%). A idade média das crianças que participaram do estudo na creche pública foi de 2 anos e 5 meses e na creche privada 2 anos e 7 meses.

$\mathrm{Na}$ analogia entre as habilidades fonológicas para cada creche foi possível observar predominância significativa para a creche privada, como demonstrado no Quadro 1. No que concerne às Habilidades Fonológicas expressivas, os dados consentem verificar que a inteligibilidade de fala foi o principal aspecto alterado entre as creches. $\mathrm{Na}$ instituição privada, 40 $(81,6 \%)$ crianças apresentaram fala compreensível, enquanto na pública apenas 16 crianças $(38,1 \%)$ exibiram essa mesma capacidade. Nas habilidades receptivas, 48 crianças (98\%) compreenderam o contexto comunicativo que lhes era apresentado, todavia na creche pública 35 crianças $(83,3 \%)$ externaram semelhante desenvoltura.

Quadro 1 - Comparação das Habilidades Fonológicas entre a creche pública e privada

\begin{tabular}{|l|c|c|c|c|c|}
\hline \multirow{1}{*}{$\begin{array}{l}\text { Habilidades } \\
\text { Fonológicas }\end{array}$} & \multicolumn{2}{|c|}{ Pública } & \multicolumn{2}{c|}{ Privada } & \\
\cline { 2 - 6 } & $\mathbf{N}$ & $\mathbf{\%}$ & $\mathbf{N}$ & $\mathbf{\%}$ & $\boldsymbol{p}$-valor \\
\hline Fala Ininteligível & 9 & $21,40 \%$ & 2 & $4,10 \%$ & 0,011 \\
\hline $\begin{array}{l}\text { Fala parcialmente } \\
\text { ininteligível }\end{array}$ & 15 & $35,70 \%$ & 7 & $14,30 \%$ & 0,017 \\
\hline Fala inteligível & 16 & $38,10 \%$ & 40 & $81,60 \%$ & $<0,001$ \\
\hline $\begin{array}{l}\text { Compreensão do } \\
\text { enunciado/contexto }\end{array}$ & 35 & $83,30 \%$ & 48 & $98,00 \%$ & 0,014 \\
\hline $\begin{array}{l}\text { Uso de palavras } \\
\text { simples }\end{array}$ & 20 & $47,60 \%$ & 14 & $28,60 \%$ & 0,061 \\
\hline $\begin{array}{l}\text { Uso de palavras } \\
\text { complexas }\end{array}$ & 15 & $35,70 \%$ & 27 & $55,10 \%$ & 0,064 \\
\hline $\begin{array}{l}\text { Teste de igualdade de duas proporções } \\
\text { N=Número de indivíduos } \\
\text { * } p<0,05\end{array}$ \\
Fonte: Dados da pesquisa
\end{tabular}

Na comparação das habilidades morfossintáticas, como formação de frase e conjugação de verbos, constatou-se pouca significância entre as instituições. A princípio se supôs que os infantes em instituições privadas teriam as habilidades morfossintáticas mais desenvolvidas pelo favorecimento econômico e social, porém se percebeu que os resultados entre as crianças foram semelhantes. Isto ocorreu, provavelmente, pelo contato pleno com estímulos indispensáveis para aquisição da estrutura linguística do idioma, como diálogo entre pares da mesma faixa etária, atividades como: conto de história e brincadeiras lúdicas. Somente no uso de orações negativas (63,3\% creche privada e $42,9 \%$ creche pública), e em especial no uso de orações interrogativas, houve melhor desempenho das crianças da creche privada $(65,3 \%)$ perante a pública $(42,9 \%)$. Esses dados podem ser observados no Quadro 2. 
Quadro 2 - Comparação das Habilidades Morfossintáticas entre a creche pública e privada

\begin{tabular}{|c|c|c|c|c|c|}
\hline \multirow{2}{*}{$\begin{array}{c}\text { Habilidades } \\
\text { Morfossintáticas }\end{array}$} & \multicolumn{2}{|c|}{ Pública } & \multicolumn{2}{|c|}{ Privada } & \multirow{2}{*}{$\boldsymbol{N}$-valor } \\
\cline { 2 - 5 } & $\mathbf{N}$ & $\mathbf{\%}$ & $\mathbf{N}$ & $\mathbf{\%}$ & \\
\hline Holofrase & 5 & $11,90 \%$ & 5 & $10,20 \%$ & 0,796 \\
\hline Fala Telegráfica & 15 & $35,70 \%$ & 18 & $36,70 \%$ & 0,920 \\
\hline $\begin{array}{c}\text { Sequência de três } \\
\text { elementos (NVN) }\end{array}$ & 22 & $52,40 \%$ & 26 & $53,10 \%$ & 0,948 \\
\hline Orações Negativas & 18 & $42,90 \%$ & 31 & $63,30 \%$ & 0,052 \\
\hline $\begin{array}{c}\text { Orações } \\
\text { interrogativas }\end{array}$ & 18 & $42,90 \%$ & 32 & $65,30 \%$ & 0,032 \\
\hline
\end{tabular}

Teste de igualdade de duas proporções. $\mathrm{N}=$ Número de indivíduos. * $p<0,05$

Fonte: Dados da pesquisa.

O reconhecimento de significados de palavras e a expressão de conceitos e motivos de preferências configuram os aspectos fundamentais da aquisição das habilidades semânticas. O Quadro 3 demonstra os resultados obtidos em ambas as creches e a significância desses achados: todas as crianças da instituição particular reconheceram palavras e $85,7 \%$ expressaram suas ideias pela fala, ao passo que no estabelecimento público $83,3 \%$ e $40,5 \%$ das crianças, respectivamente, fizeram o mesmo.

Quadro 3 - Comparação das Habilidades Semânticas entre a creche pública e privada

\begin{tabular}{|c|c|c|c|c|c|}
\hline \multirow{2}{*}{$\begin{array}{c}\text { Habilidades } \\
\text { Semânticas }\end{array}$} & \multicolumn{2}{|c|}{ Pública } & \multicolumn{2}{c|}{ Privada } & \\
\cline { 2 - 6 } & $\mathbf{N}$ & $\mathbf{\%}$ & $\mathbf{N}$ & $\mathbf{\%}$ & $\boldsymbol{p}$-valor \\
\hline $\begin{array}{c}\text { Reconhecimento } \\
\text { de palavras }\end{array}$ & 35 & $83,30 \%$ & 49 & $100,00 \%$ & 0,003 \\
\hline $\begin{array}{c}\text { Reconhecimento } \\
\text { de frases }\end{array}$ & 31 & $73,80 \%$ & 43 & $87,80 \%$ & 0,089 \\
\hline $\begin{array}{c}\text { Seleção de } \\
\text { palavras adequadas }\end{array}$ & 21 & $50,00 \%$ & 45 & $91,80 \%$ & $<0,001$ \\
\hline $\begin{array}{c}\text { Expressões de } \\
\text { ideias e conceitos }\end{array}$ & 17 & $40,50 \%$ & 42 & $85,70 \%$ & $<0,001$ \\
\hline
\end{tabular}

Teste de igualdade de duas proporções. N=Número de indivíduos. * $p<0,05$

Fonte: Dados da pesquisa.
As habilidades pragmáticas foram as que obtiveram maiores diferenças entre as creches, conforme é apresentado no Quadro 4. Todos os aspectos avaliados apresentaram resultados significantes no desempenho das crianças da creche particular em confronto com as da creche pública.

Quadro 4 - Comparação das Habilidades Pragmáticas entre a creche pública e privada

\begin{tabular}{|c|c|c|c|c|c|}
\hline \multirow{2}{*}{$\begin{array}{c}\text { Habilidades } \\
\text { Pragmáticas }\end{array}$} & \multicolumn{2}{|c|}{ Pública } & \multicolumn{2}{c|}{ Privada } & \\
\cline { 2 - 6 } & $\mathbf{N}$ & $\mathbf{\%}$ & $\mathbf{N}$ & $\%$ & $\boldsymbol{p}$-valor \\
\hline $\begin{array}{c}\text { Interação } \\
\text { comunicativa }\end{array}$ & 35 & $83,30 \%$ & 49 & $98,00 \%$ & 0,014 \\
\hline $\begin{array}{c}\text { Intencionalidade } \\
\text { em situação de fala }\end{array}$ & 29 & $69,00 \%$ & 43 & $93,90 \%$ & 0,002 \\
\hline $\begin{array}{c}\text { Organização de } \\
\text { turnos no diálogo }\end{array}$ & 14 & $33,30 \%$ & 45 & $75,50 \%$ & $<0,001$ \\
\hline Mantém diálogo & 13 & $31,00 \%$ & 42 & $71,40 \%$ & $<0,001$ \\
\hline
\end{tabular}

Teste de igualdade de duas proporções. N=Número de indivíduos. * $p<0,05$

Fonte: Dados da Pesquisa.

Em relação à alimentação das crianças que frequentam ambas as creches (Quadro 5) foram obtidos resultados semelhantes, concernentes à consistência alimentar, postura e utensílios utilizados nas refeições, bem como as ocorrências durante a alimentação. Entretanto, no uso do bico de mamadeira os resultados foram distintos: 13 (26,5\%) das crianças da creche privada utilizaram mamadeira com bico ortodôntico, enquanto na creche pública nenhuma criança usava. A mamadeira com bico comum foi utilizada por $42,9 \%$ das crianças da creche pública, e na creche privada nenhuma criança utilizou.

Quadro 5 - Comparação da Alimentação entre creche pública e privada

\begin{tabular}{|c|c|c|c|c|c|c|}
\hline \multirow{2}{*}{\multicolumn{2}{|c|}{ Alimentação }} & \multicolumn{2}{|c|}{ Pública } & \multicolumn{2}{|c|}{ Privada } & \multirow{3}{*}{$\begin{array}{r}\boldsymbol{p} \text {-valor } \\
0,416\end{array}$} \\
\hline & & \multirow{2}{*}{$\begin{array}{c}\mathbf{N} \\
3 \\
\end{array}$} & \multirow{2}{*}{$\begin{array}{c}\% \\
7,1 \% \\
\end{array}$} & \multirow{2}{*}{$\begin{array}{c}\mathbf{N} \\
6\end{array}$} & \multirow{2}{*}{$\begin{array}{c}\% \\
12,2 \% \\
\end{array}$} & \\
\hline Concistência & Semissólida & & & & & \\
\hline Consistencia & Sólida & 39 & $92,9 \%$ & 43 & $87,8 \%$ & 0,416 \\
\hline \multirow{3}{*}{ Postura de alimentação } & Sentado & 35 & $83,3 \%$ & 44 & $89,8 \%$ & 0,364 \\
\hline & Decúbito Dorsal & 1 & $2,4 \%$ & 0 & $0,0 \%$ & 0,277 \\
\hline & Sentado inadequadamente & 6 & $14,3 \%$ & 5 & $10,2 \%$ & 0,552 \\
\hline \multirow{4}{*}{ Utensílios utilizados } & Mamadeira bico comum & 18 & $42,9 \%$ & 0 & $0,0 \%$ & $<0,001$ \\
\hline & Mamadeira bico ortodôntico & 0 & $0,0 \%$ & 13 & $26,5 \%$ & $<0,001$ \\
\hline & Copo & 42 & $100,0 \%$ & 49 & $100,0 \%$ & 1,000 \\
\hline & Colher e Prato & 42 & $100,0 \%$ & 49 & $100,0 \%$ & 1,000 \\
\hline \multirow{3}{*}{ Independência Alimentar } & Alimentação com ajuda & 2 & $4,8 \%$ & 4 & $8,2 \%$ & 0,515 \\
\hline & Alimentação parcialmente com ajuda & 21 & $50,0 \%$ & 23 & $46,9 \%$ & 0,771 \\
\hline & Alimentação independente & 2 & $4,8 \%$ & 24 & $49,0 \%$ & $<0,001$ \\
\hline \multirow{2}{*}{ Ocorrências durante a alimentação } & Escape oral de alimentos & 35 & $83,3 \%$ & 43 & $87,8 \%$ & 0,548 \\
\hline & Dificuldade de mastigação & 3 & $7,1 \%$ & 4 & $8,2 \%$ & 0,855 \\
\hline
\end{tabular}

Teste de igualdade de duas proporções. N=Número de indivíduos. * $p<0,05$

Fonte: Dados da pesquisa. 
A independência alimentar apresentou achados discrepantes, visto que na creche particular $24(49 \%)$ crianças se alimentavam independentemente, enquanto na creche pública somente $2(4,8 \%)$ crianças obtiveram o mesmo feito.

\subsection{Discussão}

Segundo dados da Secretaria Municipal de Educação de Fortaleza, estão matriculados, em 2018, na rede municipal de ensino 26.249 alunos nas pré-escolas. Não há informação do número de crianças que frequentam creches particulares no Município sob estudo, nem dados precisos do número de crianças que frequentam creches no Brasil, contudo se estima que 600 mil crianças de três até cinco anos de idade ainda não são atendidas em instituições de Educação Infantil no país (MEDEIRA, 2018).

Segundo o Ministério da Saúde (2016), foi constatado que a maior parte dos pesquisados (equivalente a $61 \%$ das crianças) obteve desempenho no desenvolvimento lexical baixo comparado ao que se espera para a respectiva faixa etária, como entender ordens complexas, resumir uma historinha, relacionar ideia a objeto, cantar músicas, usar orações empregando 4 a 5 palavras, possuir vocabulário de quase 1000 palavras, repetir onomatopeias, palavras, frases e orações, entre outros. Sendo que $20 \%$ das crianças apresentaram atraso no vocabulário expressivo. Essa proporção, de acordo com o autor, decorre da característica sociocultural das crianças e de suas famílias, que viviam em condições precárias e tinham pouco acesso a níveis de educação adequados (BRASIL, 2016). A literatura correlaciona baixo nível socioeconômico com atrasos no desenvolvimento infantil referentes à performance linguística, especificamente, o vocabulário expressivo e uso de palavras e frases (ARAÚJO, 2010). Esses achados também foram evidenciados neste estudo, em que as crianças da creche pública se encontraram um pouco abaixo do esperado para sua faixa etária, conforme descrito nos Quadros 1 e 3.

Moreti et al. (2017), que verificaram a associação entre idade, nível socioeconômico e o desempenho em prova de vocabulário emissivo e receptivo de crianças pré-escolares com desenvolvimento típico de linguagem, revelaram que os vocabulários são condizentes com a faixa etária com influência do nível socioeconômico.

As 89 crianças deste estudo foram divididas em grupos semelhantes, contudo, os resultados expõem o impacto que a realidade social, ambiental, econômica e cultural distintas produz no desenvolvimento linguístico infantil, já que nas creches investigadas os estímulos foram similares.

Entre os fatores diferenciais, entre as instituições, se observou que o espaço físico e o número de crianças por sala de aula foram os achados mais prevalentes, tendo a creche privada mais espaço de lazer, maior oferta de brinquedos e menor proporção de crianças por educadora. Verificou-se ainda um número maior de atividades pedagógicas na creche privada que requeriam respostas verbais ou instigassem a comunicação. Na creche pública, as atividades estimulavam mais o desenvolvimento motor em detrimento do linguístico, pois eram na maior parte, estratégias psicomotoras.

Befi et al. (2007) apresentaram que nas Creches do Município de São Paulo foram investigadas as habilidades morfossintáticas, com ênfase no uso do verbo intransitivo, em um contexto de holofrase ou com apoio de um substantivo, configurando assim a fala telegráfica. Esse achado foi utilizado frequentemente por crianças de dois a quatro anos de idade, com destaque para o uso de verbos de forma compreensível insertos no âmbito de enunciação. Neste estudo, entretanto, as crianças de ambas as instituições demonstraram maior evolução na aquisição das habilidades morfossintáticas, já fazendo uso de frases com três elementos nessa faixa etária.

Nesta pesquisa, a fala ininteligível teve baixa ocorrência, apesar de ainda estarem na fase de aquisição fonético/ fonológica e, por vezes, aparecerem algumas dificuldades articulatórias nesta idade. As crianças já são mais claras na sua comunicação, especialmente, as que têm contato com outras crianças (HAGE et al., 2017).

Souza et al. (2008) sugerem que o ambiente familiar e cultural influenciam na aquisição das habilidades comunicativas das crianças, principalmente relacionadas à conversação. Uma comparação no desenvolvimento de fala de crianças de creches públicas e particulares no segundo ano de vida constatou que as crianças da creche pública tiveram desempenho inferior no que concerne à comunicação emissiva e receptiva da linguagem.

Carneito et al. (2009) expõem sobre a compreensão gramatical de crianças de níveis socioculturais distintos, demonstrando o fato de que as de baixa renda apresentaram nível de compreensão inferior, quando comparadas ao grupo de classe média alta na mesma faixa etária. Nesse ensaio se evidenciou que as crianças com fatores de riscos, como nível de escolaridade dos pais e condições financeiras da família, provocaram grande influência na aquisição da linguagem, no desenvolvimento cognitivo e no desempenho escolar da criança. Na creche pública se observou que há crianças com desempenho inferior comparado a outros colegas de sala, que não se comunicam verbalmente como deveriam ou apresentam sinais de alerta para atrasos no desenvolvimento da linguagem. Esses episódios não ocorreram na creche privada, demonstrando a implicação que os fatores de riscos para o desenvolvimento infantil também interferem na linguagem.

Outro aspecto contemplado no presente estudo diz respeito à alimentação, analisada mediante a observação de momentos de refeição das crianças nas creches, quando se procurou vêlas no contexto social no qual estavam inseridas e observálas se alimentando da forma como fazem no cotidiano, sem quaisquer intervenções, objetivando achados fidedignos. Diferentemente do que foi suposto, não houve variedade de dados significantes na comparação entre as creches. A maioria das crianças, de ambas as creches, já se alimenta de sólidos, 
utilizando colher, prato e copo na postura sentada, padrão adequado para essa faixa etária. Alguns estudos, no entanto, evidenciam crianças com mesma idade cronológica que ainda têm dificuldades na alimentação, principalmente, com relação à consistência sólida e ao uso da colher sem ajuda de um adulto (AMARO, 2015).

Mesmo não fazendo parte do protocolo de avaliação deste experimento, muitas mães, sobretudo, as da creche pública, relataram persistir no uso da mamadeira pela praticidade na alimentação do filho, razão pela qual não ofertavam com frequência alimentos sólidos e na colher. No Quadro 5 ficou evidente o uso persistente da mamadeira por tempo superior ao recomendado em ambas as creches, modificando-se apenas o formato do bico adotado, reflexo da instrução social e condição financeira.

Apesar de as famílias não terem trazido os alimentos na época correta, o fato de as crianças terem realizado a transição alimentar, de forma adequada, indica a influência positiva das creches. Visto que é um local onde se respeita a época de introdução e variação da qualidade dos alimentos oferecidos, com diferentes consistências e texturas, propiciando condições favoráveis para o desenvolvimento motor oral e da fala, consequentemente, prevenindo alterações nessas áreas (BARROS et al., 2011).

Quanto à independência alimentar, houve discrepância nos achados. Na creche privada 24 crianças (49\%) não necessitaram de qualquer auxílio para se alimentar, enquanto na creche pública, somente 2 crianças $(4,8 \%)$ mostraram a mesma independência. Apesar dessa diferença, houve alguns momentos em que as próprias crianças pediram ajuda para acelerar o processo da refeição, visto que quando elas se alimentavam sem auxílio o processo decorria mais lentamente. Apenas algumas crianças necessitavam de ajuda irrestrita para conseguirem se alimentar, fato esse ocorrido em ambas as creches.

\section{Conclusão}

Ante os resultados obtidos neste estudo se constatou que a realidade socioeconômica e cultural influencia no desenvolvimento linguístico e alimentar das crianças em creches.

Esses resultados, entretanto, foram mais evidentes no desenvolvimento da linguagem. Em relação às habilidades fonológicas se verificou uma predominância significativa, sendo a inteligibilidade de fala o principal aspecto alterado em creches.

Em relação às habilidades semânticas, também houve diferenças importantes, com melhor desempenho das crianças da creche privada. Já nas habilidades morfossintáticas não houve divergências significantes nos resultados entre as instituições.

As habilidades pragmáticas, porém, foram as que obtiveram maiores diferenças em todos os aspectos avaliados referentes à interação comunicativa, intencionalidade em situação de fala, organização de turnos e manutenção dos diálogos.

No que tange à alimentação, foram obtidos resultados semelhantes concernentes à consistência alimentar, postura e utensílios, muito embora tenha havido divergências relacionadas ao uso da mamadeira e independência alimentar.

Conclui-se, portanto, que o contexto socioeconômico, ambiental e cultural interfere no desenvolvimento da linguagem e alimentação infantil, visto que as crianças da creche particular apresentaram melhor desempenho em quase todos os aspectos avaliados.

\section{Referências}

AMARO, L.L.M. et al. Desenvolvimento infantil: comparação entre crianças que frequentaram ou não creches públicas. Rev. Bras. Crescim. Desen., v.25, n.2, p.170-176, 2015. doi: 10.7322/ jhgd.103002

ANDRADE, C.R.F. et al. $A B F W$ : teste de linguagem infantil nas áreas de fonologia, vocabulário, fluência e pragmática. Carapicuiba: Pró-Fono, 2000.

ARAUJO, M.V.M. et al. Avaliação do vocabulário receptivo de crianças pré-escolares. Rev. EduC. PUC-Minas. Psicol, v.27, n.2, p. 475-496, 2010.

BARROS, R.P. et al. Uma avaliação do impacto da qualidade da creche no desenvolvimento infantil. Pesq. Planej. Econôm., v. 41, n. 2, p. 213-232, 2011

BISCEGLI, T.S. et al. Avaliação do estado nutricional e do desenvolvimento neuropsicomotor em crianças frequentadoras de creche. Rev. Paul. Pediatr., v.25, n.4, p.337-342, 2007.

BEFI, L. D. M. et al. Aquisição de verbos em pré-escolares falantes do português brasileiro. Rev. CEFAC, v.9, n.4, p.444-452, 2007. doi: 10.1590/S1516-18462007000400003.

BRASL. Lei $\mathrm{n}^{\circ}$. 9.394, 1996. Diretrizes e bases da educação nacional. Disponível em: <http://www.planalto.gov.br/ccivil 03/ Leis/L9394.htm>.

BRASÍLIA. Diretrizes de estimulação precoce crianças de zero a 3 anos com atraso no desenvolvimento neuropsicomotor. Secretaria de Atenção à Saúde. Brasília: Ministério da Saúde, 2016.

CARNEIRO, A.S. et al. Caracterização do desenvolvimento da alimentação em crianças de 6 aos 24 meses de idade do município de Canoas/RS. Rev. CEFAC, v.11, n.2, p.1579-1588, 2009.

DEMO, P. Escola pública e escola particular: semelhanças de dois imbróglios educacionais. Ensaio Aval. Pol. Públ. Educ., v.15, n.55, 2007. doi: 10.1590/S0104-40362007000200002

GENARO, K.F. et al. Avaliação miofuncional orofacial protocolo MBGR. Rev. CEFAC, v.11, n.2, p.237-255, 2009. doi: 10.1590/S1516-18462009000200009.

HAGE, S.R.V. et al. Análise do perfil das habilidades pragmáticas em crianças pequenas normais. Pró-Fono Rev. Atual. Cient. v.9, n.1, p.49-58, 2007.

HAGUETTE, R.C.B. Ficha de coleta de dados clínicos e fonoaudiológicos. Fortaleza: Serviço de Fonoaudiologia, 2006.

LIMA, F.T. et al. Alterações fonoaudiológicas presentes em um caso de síndrome de Goldenhar. Rev. Soc. Bras. Fonoaudiol., v.12, n.2, p.141-145, 2007. doi: 10.1590/S1516-80342007000200012.

MEDEIRA, V. Acesso à pré-escola na Capital chega a 93\% das 
crianças. 2018.

MORETTI, et al. Vocabulário de pré-escolares com desenvolvimento típico de linguagem e variáveis socioeducacion ais. Comunicação Breve, v.20, n.1, p.1-4, 2017. doi: 10.1590/2317$1782 / 20172016098$

OLIVEIRA, L.D; FLORES, M.R.; SOUZA, A.P.R. Fatores de risco psíquico ao desenvolvimento infantil: implicações para a fonoaudiologia. Rev. CEFAC, v.14, n.2, p.333-342, 2012.

PALLADINO, R.R.; CUNHA, M.C.; SOUZA, L.A.P. Problemas de linguagem e alimentares em crianças: co-ocorrências ou coincidências. Pro-Fono Rev. Atual.Cient. v.19, n.2, p.205-214, 2007.

SANTOS, J.N. et al. Habilidades auditivas e desenvolvimento de linguagem em crianças. Pró-Fono. Rev. Atual. Cient. v.20, n.4, p.255-260, 2008.

SOUZA, S.C. et al. Desenvolvimento de pré-escolares na educação infantil em Cuiabá, Mato Grosso, Brasil. Cad. Saúde Pública, v.24, n.8, p. 1926-1936, 2008. 